\title{
GAYA KEPEMIMPINAN UNTUK ACCOUNT REPRESENTATIVE PADA KANTOR PELAYANAN PAJAK DI WILAYAH DKI JAKARTA
}

\author{
Maya Sari \& Yanki Hartijasti \\ Fakultas Ekonomi dan Bisnis, Universitas Indonesia \\ E-mail: mayamulu.vi@gmail.com
}

\begin{abstract}
ABSTRAK
Penelitian ini bertujuan untuk mengetahui bagaimana praktik kepemimpinan di Direktorat Jenderal Pajak (DJP) sebagai salah satu sektor publik di Indonesia. Penelitian ini juga untuk mengetahui gaya kepemimpinan yang diharapkan oleh pegawai. Responden yang terlibat sebanyak 550 Account Representative dan 68 Kepala Seksi Pengawasan dan Konsultasi dari 17 Kantor Pelayanan Pajak (KPP) di wilayah DKI Jakarta. Penelitian ini menggunakan metode qualitative content analysis. Hasil penelitian menunjukkan bahwa gaya kepemimpinan yang ditampilkan, yaitu paternalistic leadership dengan dimensi benevolent leadership, merupakan perilaku yang paling banyak ditampilkan dan dianggap berhasil. Sementara itu, ketidakberhasilan kepemimpinan dikarenakan kurang menampilkan dimensi visible leadership dan banyak menampilkan dimensi authoritarian leadership. Hasil penelitian juga menunjukkan bahwa gaya kepemimpinan yang diharapkan adalah paternalistic leadership dengan dimensi benevolent leadership sebagai perilaku yang paling banyak diinginkan.
\end{abstract}

Kata Kunci: Account Representatives; content analysis; Direktorat Jenderal Pajak; paternalistic leadership; sektor publik

Klasifikasi JEL: M10, M12, M50

\begin{abstract}
The purpose of this study is to investigate the current practices of leadership in Directorate General of Taxes, one of the public sectors in Indonesia. This study is also to determine the leadership style that is expected by employees. Respondents that were involved in this study were 550 Account Representatives and 68 Head of Supervision and Consultation Section from 17 Tax Offices (KPP) in the DKI Jakarta region. This study used a qualitative content analysis method. The results revealed that the current practices of leadership was the paternalistic leadership with the benevolent leadership dimension as the most widely displayed and considered as successful behavior. Meanwhile, leadership failure was due to lack of displayed the visible leadership dimensions and many displayed the authoritarian leadership dimension. The results also revealed a strong preference for paternalistic leadership with benevolent leadership dimension as the most expected behavior.
\end{abstract}

Keywords:Account Representatives; content analysis; Directorate General of Taxes; paternalistic leadership; public sector

JEL Classification:M10, M12, M50 


\section{Maya Sari}

\section{Yanki Hartijasti}

\section{PENDAHULUAN}

Hemsworth et al., (2013) mengatakan bahwa kepemimpinan merupakan salah satu bidang yang paling banyak dipelajari dalam literatur (Hemsworth et al., 2013). Walaupun demikian, istilah kepemimpinan sendiri memiliki pengertian yang tidak seragam (Northouse, 2013). Northouse (2013) sendiri mendefinisikan kepemimpinan sebagai proses bagaimana individu memengaruhi sekelompok individu untuk mencapai tujuan bersama (Northouse, 2013). Sementara itu, Armstrong (2016) mendefinisikan kepemimpinan sebagai proses untuk membuat setiap orang melakukan yang terbaik untuk mencapai hasil yang diinginkan (Armstrong, 2016).

Pemimpin memainkan peran yang sangat penting dan biasanya bekerja di balik layar untuk kesejahteraan dan keefektifan dari usaha yang telah dilakukan oleh grup individu yang jika dilakukan sendiri-sendiri maka tidak akan mencapai tujuan bersama (Gibson et al., 2012). Wahab et al. (2016) mengatakan bahwa perilaku kepemimpinan penting dipelajari karena dapat membantu para pemimpin sekaligus organisasi untuk memanfaatkan sepenuhnya sumber daya (Wahab et al., 2016).

Pentingnya kepemimpinan telah mendapatkan perhatian banyak peneliti di seluruh penjuru dunia (Northouse, 2013). Studi yang telah dilakukan melahirkan banyak teori pendekatan kepemimpinan,misalnya teori kepemimpinan pendekatan sifat, pendekatan keterampilan, serta kepemimpinan transformasional dan transaksional (Northouse, 2013). Studi kepemimpinan tersebut dilaksanakan di negara Barat (Yukl) pada tahun 2010 yang umumnya memiliki dimensi budaya individualis dengan jarak kekuasaan rendah (Hofstede et al., 2010).

Di negara Timur studi kepemimpinan juga telah dilakukan. Serangkaian studi kepemimpinan di negara Timur misalnya dilakukan oleh Silin, Redding, dan Cheng. Mereka menemukan bahwa gaya kepemimpinan perusahaan Cina berbeda dengan gaya kepemimpinan Barat (Cheng et al., 2004). Penelitian tersebut juga berhasil mengidentifikasi karakteristik penting dari paternalistic leadership yaitu authoritarian, moral, dan benevolent leadership (Farh \& Cheng, 2000). Gaya kepemimpinan inilah yang kemudian diberi nama paternalistic leadership oleh Westwood \& Chan(1992) dalam Cheng et al.,(2004).

Di Indonesia sendiri, telah dilakukan studi untuk mencari dimensi kepemimpinan yang sesuai dengan budaya Indonesia. Irawanto et al. (2012) melakukan penelitian mengenai penerapan paternalistic leadership pada organisasi sektor publik di Indonesia. Studi yang dilakukan terhadap 1.000 pegawai negeri sipil di Jawa Timur dan Daerah Istimewa 
Yogyakarta tersebut menggunakan explanatory factor analysis (EFA). Mereka mendapatkan tujuh dimensi paternalistic leadership di Indonesia (Irawanto et al., 2012). Penelitian lainnya dilakukan oleh Suryani et al, (2012), mengenai karakteristik kepemimpinan di Indonesia. Penelitian ini dibagi dalam tiga bagian menggunakan mixed-methods approach. Penelitian ini menemukan bahwa kepemimpinan Indonesia memiliki dua komponen, yaitu transformational-bapak-ism dan self-oriented leadership. Mereka menyimpulkan bahwa kepemimpinan Indonesia memiliki aspek emic (budaya spesifik) dan aspek etic (universal) (Suryani et al, (2012).

Walaupun studi untuk mencari dimensi kepemimpinan yang sesuai dengan budaya Indonesia telah dilakukan, namun konstruk yang ada masih perlu diuji kebenarannya. Oleh karena itu, masih perlu dilakukan penelitian lainnya khususnya penelitian kualitatif sehingga dapat menemukan atau menguatkan konstruk teori kepemimpinan di Indonesia.

Salah satu organisasi sektor publik di Indonesia yaitu Direktorat Jenderal Pajak (DJP). DJP memiliki peran penting dalam mengumpulkan penerimaan negara dari sektor perpajakan (Sakti, 2014). Direktorat Jenderal Pajak telah mengalami beberapa kali proses reformasi perpajakan (Arifin, 2016). Walaupun demikian, DJP masih belum dapat sepenuhnya memberikan hasil yang optimal. Salah satunya yaitu penerimaan pajak tidak tercapai sejak tahun 2009 (Kusuma, 2017). Untuk tahun 2017 sendiri, penerimaan perpajakan mencapai Rp 1.339,8 triliun atau mencapai 91 persen dari target APBN-P 2017 yang sebesar Rp 1.450,9 triliun (Julianto, 2018). Rasio kepatuhan penyampaian Surat Pemberitahuan (SPT) Tahunan Pajak Penghasilan (PPh) di Indonesia juga masih di bawah target. Pada tahun 2016 realisasi rasio kepatuhan penyampaian SPT hanya pada kisaran 63,15\% dari target yang hanya 72,50\% (Direktorat Jenderal Pajak, 2017). Selain itu, rasio pajak (tax ratio) Indonesia juga rendah jika dibandingkan dengan beberapa negara Asia Tenggara lain. Tax ratio Indonesia hanya pada kisaran 10 sampai 11 persen dalam lima tahun terakhir, sementara Filipina, Malaysia, dan Thailand berada pada kisaran 13 sampai 16 persen (World Bank, 2018).

Sumber Daya Manusia (SDM) memiliki kedudukan yang penting di DJP. Aparatur pajak yang berintegritas, kompeten, dan profesional serta didukung dengan sistem kompensasi yang kompetitif berbasis sistem manajemen kinerja mendukung dalam pencapaian visi dan tanggung jawab DJP (Direktorat Jenderal Pajak, 2018). Sayangnya jumlah SDM yang dimiliki DJP tidak sebanding dengan Wajib Pajak yang harus ditangani. Sampai dengan 31 Desember 2016, DJP memiliki sebanyak 40.035 pegawai, sementara jumlah Wajib Pajak terdaftar yaitu sebanyak 36.446.616 (Direktorat Jenderal Pajak, n.d.). Dengan kata lain, 1 pegawai harus menangani 911 Wajib Pajak. 


\section{Maya Sari}

\section{Yanki Hartijasti}

Salah satu aparatur pajak yang dimiliki oleh DJP adalah Account Representative.Account Representative mengemban tugas intensifikasi perpajakan melalui pemberian bimbingan/himbavan, konsultasi, analisis dan pengawasan terhadap Wajib Pajak dan merupakan salah satu ujung tombak penggalian potensi penerimaan negara di bidang perpajakan (Kementerian Kevangan Republik Indonesia, 2015). Pengawasan kepatuhan dan penggalian potensi Wajib Pajak adalah alat penting dalam pengamanan penerimaan negara sebagai konsekuensi dari self assessment system yang dianut oleh sistem perpajakan Indonesia. Sampai dengan 31 Desember 2016, DJP memiliki sebanyak 8.901 Account Representative yang tersebar di kantor-kantor di seluruh Indonesia (Direktorat Jenderal Pajak, n.d.).

Dalam struktur organisasi DJP, berdasarkan Pasal 80 ayat (6) Peraturan Menteri Keuangan Nomor 206.2/PMK.01/2014 tentang Organisasi dan Tata Kerja Instansi Vertikal Direktorat Jenderal Pajak, seorang Account Representative, baik yang berada di Kantor Pelayanan Pajak Wajib Pajak Besar, Kantor Pelayanan Pajak Madya, maupun Kantor Pelayanan Pajak Pratama, berada di bawah Seksi Pengawasan dan Konsultasi yang dipimpin oleh seorang Kepala Seksi Pengawasan dan Konsultasi. Kepala Seksi Pengawasan dan Konsultasi bertanggung jawab mengendalikan pelaksanaan kegiatan yang dilakukan oleh Account Representative (Republik Indonesia, 2014).

Mengingat pentingnya kepemimpinan dan adanya permasalahan yang ada di DJP, maka perlu dilakukan penelitian guna mengoptimalkan kinerja para pegawai DJP agar dapat berkontribusi secara maksimal dalam mencapai target penerimaan pajak. Adapun tujuan penelitian yang ingin dicapai yaitu untuk mengetahui bagaimana persepsi terkait gaya kepemimpinan yang digunakan oleh atasan Account Representative dan gaya kepemimpinan yang diharapkan Account Representative.

\section{LANDASAN TEORI}

\section{Definisi Kepemimpinan}

Kepemimpinan memiliki pengertian yang tidak seragam. Northouse (2013) mengatakan bahwa istilah kepemimpinan telah coba ditetapkan oleh para akademisi dan praktisi selama lebih dari seabad, namun akhirnya tanpa konsensus universal (Northouse, 2013). Ketidaksepakatan terkait definisi ini dikarenakan fakta bahwa kepemimpinan melibatkan interaksi yang kompleks di antara pemimpin, pengikut, dan situasi (Kreitner \& Kinicki, 2013). Northouse (2013) lebih lanjut mengatakan bahwa definisi-definisi kepemimpinan dipengaruhi oleh banyak faktor dari masalah dunia serta politik untuk perspektif tentang disiplin tempat topik tersebut dipelajari (Northouse, 2013). 


\section{Jurnal Manajemen Teori dan Terapan \\ Tahun 11. No. 2, Agustus 2018}

Dalam beberapa buku dan penelitian terbaru, dapat juga ditemukan beberapa definisi terkait kepemimpinan. Gibson et al. (2012) mendefinisikan kepemimpinan sebagai upaya untuk menggunakan pengaruh untuk memotivasi individu-individu untuk mencapai beberapa tujuan (Gibson et al., 2012). Sementara itu, Kreitner dan Kinicki (2013) mendefinisikan kepemimpinan sebagai proses seorang individu memengaruhi orang lain untuk mencapai tujuan bersama (Kreitner \& Kinicki, 2013).

\section{Pendekatan Kepemimpinan}

Teori kepemimpinan dapat dikelompokkan dalam beberapa pendekatan. Tabel 1 adalah rangkuman dari beberapa pendekatan yang berkembang.

\section{Tabel 1. Pendekatan Kepemimpinan}

1. Pendekatan Sifat (Trait) (Northouse, 2013) Stogdill (1948) - ada 8 sifat kepemimpinan yaitu: kecerdasan, kepekaan, wawasan, tanggung jawab, inisiatif, ketekunan, keyakinan diri, dan kemampuan bersosialisasi.

Zaccaro et al. (2004) - sifat kepemimpinan penting sebagai berikut: kemampuan kognitif, sifat ekstrover, kehati-hatian, kestabilan emosi, sikap terbuka, kemampuan bersosialisasi, motivasi, kecerdasan sosial, kontrol diri, kecerdasan emosional, dan pemecahan masalah.

2. Pendekatan Keterampilan (Skills) (Northouse, 2013) Katz (1955) - keterampilan pribadi dasar pemimpin: teknis, manusia, dan konseptual. Mumford et al. (2000) - komponen model kepemimpinan yaitu: kompetensi, karakter individu, hasil kepemimpinan, pengalaman karier, dan pengaruh lingkungan.

3. Pendekatan Gaya Perilaku (Style) (Northouse, 2013)

Penelitian dari Ohio State University - perilaku umum kepemimpinan: membentuk struktur dan perhatian.

Penelitian dari University of Michigan - perilaku kepemimpinan: employee orientation dan production orientation.

4. Pendekatan Transformasional dan Transaksional (Northouse, 2013)

Burn (1978) membedakan dua jenis kepemimpinan: transaksional dan transformasional. Bass dan Avolio (1994) mengembangkan Model Rentang Penuh Kepemimpinan (The full-range model of leadership) yaitu model kepemimpinan transformasional dan transaksional yang mencakup: charisma (idealized influence), inspirational motivation, intellectual stimulation, invidualized consideration, contingent reward, dan management-by-exception.

5. Kepemimpinan Paternalistik (Paternalistic Leadership)

Redding (1990): authoritarian leadership, moral leadership, dan benevolent leadership (Farh \& Cheng, 2000).

Irawanto et al. (2012): visible leadership; authoritarian leadership; benevolent leadership; moralincorruptness leadership; moral-courage leadership; moral-magnanimity leadership; dan moralimpartialness leadership (Irawanto et al., 2012).

Sumber: Northouse (2013); Farh \& Cheng (2000); Irawanto et al. (2012) 


\section{Maya Sari}

\section{Yanki Hartijasti}

Tabel 1 menunjukkan bahwa ada beberapa pendekatan dalam teori kepemimpinan. Misalnya yaitu pendekatan sifat (trait), pendekatan keterampilan (skills), pendekatan gaya perilaku (style), pendekatan transformasional dan transaksional, dan kepemimpinan paternalistik (paternalistic leadership). Teori kepemimpinan tersebut dibangun berdasarkan hasil studi kepemimpinan,seperti studi yang dilakukan oleh Zaccaro et al. (2004) dalam Northouse(2013) terkait teori kepemimpinan pendekatan sifat (trait) (Northouse, 2013).

\section{METODE PENELITIAN}

\section{Sampel}

Penelitian ini melibatkan Account Representative (AR) dan atasan langsungnya (Kepala Seksi Pengawasan dan Konsultasi) yang ada di Kantor Pelayanan Pajak (KPP) di wilayah DKI Jakarta. AR dipilih karena merupakan salah satu ujung tombak penggalian potensi penerimaan negara di bidang perpajakan (Kementerian Keuangan Republik Indonesia, 2015). Sementara itu, KPP di wilayah DKI Jakarta dipilih dengan pertimbangan memiliki jumlah penerimaan pajak terbesar dibanding wilayah lainnya.

Penelitian ini menggunakan metode purposive sampling sebagai teknik penarikan sampel. Sampel dipilih dengan memertimbangkan persentase capaian kantor yaitu rata-rata persentase capaian KPP atas target penerimaan pajak selama lima tahun berturut-turut. Terdapat 10 kantor dengan capaian tertinggi dan 10 kantor dengan capaian terendah dari 73 KPP yang ada di wilayah DKI Jakarta. Dari 20 kantor yang akan dijadikan sampel, Jumah responden dari 17 kantor tersebut yaitusebanyak 550 AR dan 68 Kepala Seksi Pengawasan dan Konsultasi.

\section{Pengumpulan Data}

Masing-masing responden diberikan pertanyaan-pertanyaan tertulis dalam bentuk kuesioner dengan pertanyaan terbuka. Kuesioner ini merupakan pengganti panduan wawancara yang biasa digunakan dalam wawancara terstruktur. Cooper \& Schindler (2014) menyatakan wawancara terstruktur seringnya menggunakan panduan wawancara detail yang mirip dengan kuesioner untuk memandu pertanyaan dan sebagai cara spesifik dalam menyampaikan pertanyaan, namun umumnya pertanyaannya terbuka. Responden diberikan dua opsi yaitu mengisi melalui kuesioner kertas (hardcopy) atau melalui kuesioner online (Cooper \& Schindler, 2014).

\section{Pengukuran dan Metode Analisis Data}

Northouse (2013) mengatakan bahwa kepemimpinan merujuk pada apa yang seseorang lihat dalam diri orang lain ketika mereka menampilkan perilaku kepemimpinan. Oleh karena 
itu, kepemimpinan dalam penelitian ini dinilai berdasarkan perilaku atasan (Northouse, 2013). Adapun pertanyaan terbuka yang dimasukkan dalam kuesioner merupakan modifikasi dari pertanyaan dalam wawancara dan FGD yang digunakan oleh Suryani et al. (2012) dalam penelitiannya. Pertanyaan tersebut didasarkan pada tinjauan perilaku manajemen menurut Yukl (2004) dalam Suryani et al.(2012). Mereka berpendapat bahwa pendekatan yang efektif untuk mengidentifikasi ciri kepemimpinan, perilaku, dan gaya kepemimpinan, yaitu dengan menanyakan bagaimana pemimpin mengelola organisasinya. Dalam kuesioner penelitian ini, beberapa pertanyaan terbuka yang diajukan sebagaimana dapat dilihat pada tabel 2.

\section{Tabel 2. Pertanyaan Kuesioner}

\begin{tabular}{|c|c|}
\hline $\begin{array}{l}\text { Perilaku yang } \\
\text { dinilai }\end{array}$ & Bentuk Pertanyaan \\
\hline Berhasil & $\begin{array}{l}\text { Dari pengalaman di tempat kerja Bapak/lbu saat ini (sebagai AR), perilaku } \\
\text { seperti apa yang ditampilkan oleh atasan langsung yang menyebabkan beliau } \\
\text { berhasil dalam mengelola anak buahnya? Sampaikan } 3 \text { perilaku dan contoh } \\
\text { spesifiknya. }\end{array}$ \\
\hline $\begin{array}{l}\text { Tidak/kurang } \\
\text { berhasil }\end{array}$ & $\begin{array}{l}\text { Dari pengalaman di tempat kerja Bapak/lbu saat ini (sebagai AR), perilaku } \\
\text { seperti apa yang ditampilkan oleh atasan langsung yang menyebabkan beliau } \\
\text { tidak/kurang berhasil dalam mengelola anak buahnya? Sampaikan } 3 \text { perilaku } \\
\text { dan spesifiknya. }\end{array}$ \\
\hline Pemberian tugas & $\begin{array}{l}\text { Dari pengalaman di tempat kerja Bapak/lbu saat ini (sebagai AR), perilaku } \\
\text { seperti apa yang ditampilkan oleh atasan langsung terkait pemberian tugas? }\end{array}$ \\
\hline $\begin{array}{l}\text { Hubungan } \\
\text { personal }\end{array}$ & $\begin{array}{l}\text { Dari pengalaman di tempat kerja Bapak/lbu saat ini (sebagai AR), perilaku } \\
\text { seperti apa yang ditampilkan oleh atasan langsung terkait hubungan personal } \\
\text { dengan bawahan? }\end{array}$ \\
\hline
\end{tabular}

\section{Sumber: Kuesioner penelitian}

Analisis data dilakukan dengan menggunakan teknik qualitative content analysis. Content analysis adalah teknik penelitian untuk menarik kesimpulan yang valid dan replicable dari sebuah teks (atau hal lainnya yang memiliki arti) sesuai dengan konteks kegunaannya (Krippendorff, 2012). Langkah-langkah content analysis dalam penelitian ini merujuk pada langkah-langkah Schreier (2014) dan Mayring (2014) yaitu: (1) menentukan research question dan theoretical background; (2) memilih data; (3) membangun kerangka pengodean; (4) percobaan pengodean; (5) mengevaluasi dan memodifikasi kerangka pengodean; (6) analisis utama; dan (7) mempresentasikan dan menginterpretasikan temuan. 


\section{Maya Sari}

\section{Yanki Hartijasti}

\section{HASIL DAN PEMBAHASAN}

Terdapat 200 kuesioner dari AR (response rate 36,4\%) dan 22 kuesioner dari atasan langsung (response rate $32,4 \%$ ) dari seluruh kuesioner yang disebar. Kuesioner yang telah diisi kemudian diolah untuk dianalisis. Pada tahap ini peneliti melakukan rekap atas seluruh kuesioner. Hanya 75 responden $(33,78 \%)$ yang mengisi secara online dari 222 kuesioner yang masuk. Sisanya sebanyak 147 kuesioner diinput datanya ke dalam aplikasi Excel. Seluruh data kemudian disatukan ke dalam satu kertas kerja (worksheet). Peneliti kemudian membangun kerangka pengodean. Hal yang pertama dilakukan peneliti pada tahap ini yaitu membaca keseluruhan data untuk membangun general sense terhadap informasi. Peneliti juga berusaha untuk menangkap gagasan inti dari masing-masing jawaban responden yang digunakan untuk membangun kerangka pengodean.

Selanjutnya peneliti melakukan structuring dan generating kategori. Structuring kategori adalah menciptakan kategori utama, sementara generating kategori adalah menciptakan subkategori untuk masing-masing kategori utama. Kategori utama dalam penelitian ini adalah pertanyaan-pertanyaan dalam kuesioner yang menggambarkan perilaku kepemimpinan. Setiap pertanyaan mewakili 1 kategori utama sehingga terdapat 10 kategori utama mewakili 10 pertanyaan dalam kuesioner.

Subkategori dibuat berdasarkan jawaban responden pada masing-masing pertanyaan. Peneliti mengidentifikasi secara langsung jawaban responden, kemudian mengategorikannya berdasarkan kemiripan perilaku. Jawaban dengan kata kunci (keyword) atau tema yang sama dimasukkan ke dalam satu subkategori. Contohnya untuk pertanyaan terkait perilaku berhasil dalam mengelola anak buah, jawaban responden kemudian dikategorikan dalam subkategori "Memberi teladan", "Membimbing/mengarahkan", atau "Memotivasi". Nama kategori tersebut merupakan kata atau frasa yang paling cocok menggambarkan topik dalam kategori tersebut.

Setelah semua kategori dibuat, kemudian dilakukan percobaan pengodean dengan memasukkan jawaban responden ke dalam masing-masing subkategori. Proses ini dilakukan bertahap untuk masing-masing pertanyaan. Pada proses ini juga dilakukan segmentasi (segmentation) yaitu proses untuk membagi jawaban responden ke dalam bagian-bagian sehingga setiap bagian dapat tepat masuk ke dalam satu subkategori (Schreier, 2014). Hal tersebut dilakukan karena dalam satu jawaban responden, dimungkinkan terdapat lebih dari satu tema atau kata kunci. Oleh karena itu, dilakukan pemisahan jawaban responden sehingga dari satu jawaban dapat dimasukkan ke dalam lebih dari satu subkategori. Contohnya yaitu untuk perilaku kepemimpinan yang berhasil dalam mengelola anak buah, 
responden nomor 4 memberikan jawaban "mengayomi dan pengertian terhadap bawahan". Saat dilakukan kategorisasi, jawaban tersebut dapat masuk ke dalam dua subkategori yaitu subkategori "Mengayomi atau melindungi anak buah" dan subkategori "Pengertian".

Setelah dilakukan percobaan pengodean, peneliti melakukan evaluasi dan modifikasi kerangka pengodean jika dirasa masih ada kategori yang kurang tepat. Jika masih ada jawaban yang belum memiliki subkategori, maka dibuat subkategori baru. Untuk jawaban yang tidak relevan dengan pertanyaan, maka diberi label "Di luar konteks", untuk kemudian tidak dimasukkan dalam analisis lebih lanjut. Peneliti juga memeriksa kualitas penamaan subkategori. Beberapa nama subkategori memiliki makna yang ambigu dan diganti agar dapat tepat menggambarkan tema yang tercakup dalam subkategori tersebut. Contohnya yaitu "Saleh" menjadi "Agamis". Selain itu, peneliti juga melakukan penggabungan beberapa subkategori yang masih dapat dimasukkan ke dalam satu subkategori, misalnya "Jujur" dan "Integritas" dikategorikan sebagai "Berintegritas". Proses penggabungan ini mengurangi jumlah subkategori.

Peneliti kemudian melakukan pengodean kepada seluruh jawaban responden. Setelah seluruh jawaban dimasukkan ke dalam subkategori masing-masing, kemudian dilakukan pengelompokan per subkategori yaitu menghitung frekuensi masing-masing subkategori. Peneliti lalu membagi jawaban terkait persepsi kepemimpinan yang ditampilkan menjadi 2 kelompok besar yaitu perilaku yang dianggap berhasil dan perilaku yang dianggap tidak berhasil.

Perilaku yang telah dikelompokkan tersebut kemudian dikategorikan lagi ke dalam tematema besar mengacu pada dimensi-dimensi dalam teori kepemimpinan. Dalam tahap ini dilakukan triangulasi teori dengan mencoba beberapa dimensi teori kepemimpinan yang berbeda. Pertama-tama, proses triangulasi dilakukan dengan menggunakan dimensidimensi dari teori kepemimpinan pendekatan sifat, pendekatan gaya perilaku, pendekatan keterampilan, transformasional, transaksional, dan paternalistic leadership. Pendekatan sifat yang digunakan salah satunya yaitu dari Zaccaro et al. (2004) dalam Northouse(2013) yang menggambarkan sifat kepemimpinan penting yaitu kemampuan kognitif, sifat ekstrover, kehati-hatian, kestabilan emosi, sikap terbuka, kemampuan bersosialisasi, motivasi, kecerdasan sosial, kontrol diri, kecerdasan emosional, dan pemecahan masalah (Northouse, 2013). Pada penelitian ini, tidak seluruh sifat kepemimpinan yang disebutkan dalam teori dapat ditemukan dalam jawaban responden. Namun, dalam penelitian ini juga ditemukan sifat kepemimpinan yang tidak disebutkan dalam teori misalnya yaitu sifat tegas, berintegritas, konsisten, dan rapi. 


\section{Maya Sari}

\section{Yanki Hartijasti}

Teori kepemimpinan pendekatan keterampilan (skills) yang digunakan dalam proses triangulasi adalah teori kepemimpinan dari Katz (1955) dalam Northouse(2013) yaitu kepemimpinan yang efektif bergantung pada tiga keterampilan pribadi dasar: teknis, manusia, dan konseptual (Northouse, 2013). Pada penelitian ini ditemukan dua keterampilan dasar yang dimiliki oleh atasan langsung AR yaitu keterampilan teknis dan keterampilan manusia. Keterampilan teknis yang muncul dalam jawaban responden yaitu penguasaan atas peraturan perpajakan, teknis perpajakan, Standard Operating Procedure (SOP), dan penguasaan teknologi. Sementara itu, keterampilan manusia yang muncul dalam jawaban responden yaitu bekerja sama/sinergi, memberi kepercayaan, dan memberi motivasi.

Pendekatan gaya perilaku yang digunakan yaitu hasil penelitian dari University of Michigan olehBower \& Seashore(1966) dalam Northouse(2013) mengidentifikasi dua jenis perilaku kepemimpinan yaitu employee orientation dan production orientation (Northouse, 2013). Pada penelitian ini employee orientation ditunjukkan dengan perilaku atasan yang perhatian/peduli pada bawahan, saling menghargai/saling menghormati, serta dekat/akrab dengan bawahan. Sementara itu, production orientation ditunjukkan dengan perilaku atasan yang berorientasi terhadap pencapaian target, memonitor pekerjaan anak buah, serta memberikan target yang tinggi.

Pendekatan selanjutnya yang digunakan yaitu kepemimpinan transformasional dan transaksional. Menurut Bass \& Avolio (1994) dalam Northouse (2013), kepemimpinan transformasional memiliki 4 dimensi yaitu charisma (idealized influence), inspirational motivation, intellectual stimulation, dan individualized consideration, sementara kepemimpinan transaksional memiliki 2 dimensi yaitu contingent reward dan managementby-exception (Northouse, 2013). Pada penelitian ini, dimensi kepemimpinan transformasional muncul dalam jawaban responden misalnya memberi teladan (idealized influence), memotivasi (inspirational motivation), menerima masukan (intellectual stimulation), dan membimbing/mengarahkan anak buah (individualized consideration). Sementara itu, dimensi-dimensi kepemimpinan transaksional tidak muncul dalam jawaban responden.

Pendekatan terakhir yang digunakan yaitu paternalistic leadership. Dimensi paternalistic leadership dalam penelitian ini menggunakan hasil penelitian Irawanto et al. (2012) yaitu authoritarian leadership, benevolent leadership, moral-courage leadership, moralimpartialness leadership, moral-incorruptness leadership, moral-magnanimity leadership, dan visible leadership. Pada penelitian ini, semua dimensi dari paternalistic leadership muncul dalam jawaban responden (Irawanto et al., 2012). 
Pada proses triangulasi pertama ini, ditemukan bahwa terjadi tumpang tindih antara satu dimensi dengan dimensi lainnya. Contohnya yaitu perilaku "Tanggung jawab" yang masuk ke dalam dimensi pendekatan sifat, tetapi dapat juga masuk ke dalam paternalistic leadership yaitu dimensi visible leadership. Contoh lainnya yaitu perilaku "Memotivasi" yang masuk ke dalam dimensi keterampilan manusia pada pendekatan keterampilan, dapat juga masuk ke dalam kepemimpinan transformasional yaitu inspirational motivation. Katz (1955) dalam Northouse(2013) mengatakan bahwa menjadi pemimpin dengan keterampilan manusia berarti peka terhadap kebutuhan dan motivasi orang lain serta memertimbangkan kebutuhan orang lain di dalam pengambilan keputusan. Definisi ini mirip dengan dimensi inspirational motivation pada kepemimpinan transformasional misalnya yaitu pemimpin menginspirasi bawahan melalui motivasi untuk berkomitmen menjadi bagian dari visi bersama dalam organisasi (Northouse, 2013).

Contoh selanjutnya yaitu perilaku "Orientasi terhadap pencapaian target" yang masuk ke dalam dimensi production orientation pada pendekatan gaya perilaku, dapat juga masuk ke dalam paternalistic leadership yaitu dimensi authoritarian leadership. Bower \& Seashore (1966) mengatakan dalam Northouse (2013) Production orientation adalah perilaku kepemimpinan yang menekankan aspek teknis dan produksi dari suatu pekerjaan (Northouse, 2013). Selain itu, perilaku "Perhatian/peduli" yang masuk ke dalam dimensi employee orientation pada pendekatan gaya perilaku, dapat juga masuk ke dalam kepemimpinan transformasional yaitu individualized consideration. Selanjutnya Bower \& Seashore (1966) menjelaskan bahwa Employee orientation adalah perilaku pemimpin yang mendekati pengikut dengan penekanan hubungan antar manusia yang kuat dengan menganggap karyawan sebagai manusia, menghargai individualitas mereka, memberi perhatian khusus untuk kebutuhan pribadinya(Northouse, 2013). Definisi ini mirip dengan dimensi individualized consideration pada kepemimpinan transformasional misalnya yaitu pemimpin memberikan iklim yang mendukung dengan mendengarkan secara seksama kebutuhan individu para pengikut (Northouse, 2013).

Proses triangulasi selanjutnya dilakukan hanya dengan menggunakan dimensi-dimensi teori kepemimpinan transformasional dan paternalistic leadership. Hal tersebut dikarenakan telah terjadi tumpang tindih antar pendekatan kepemimpinan. Kedua pendekatan ini dipilih karena dianggap telah mencakup pendekatan kepemimpinan lainnya (sifat, keterampilan, gaya perilaku). Kepemimpinan transaksional juga tidak dimasukkan kembali ke dalam proses triangulasi karena tidak muncul dalam jawaban responden.

Pada proses triangulasi kedua ini, didapatkan pula bahwa dimensi kepemimpinan transformasional tumpang tindih dengan dimensi paternalistic leadership. Hal ini sejalan 


\section{Maya Sari}

\section{Yanki Hartijasti}

dengan yang dikatakan Cheng et al. (2004) yang mengatakan bahwa kepemimpinan transformasional memiliki tiga dimensi yang hampir mirip dengan yang ada di paternalistic leadership. Tiga dimensi tersebut yaitu individualized consideration dengan benevolent leadership, modeling dengan moral leadership, dan high performance emphasis dengan authoritarian leadership.

Dimensi individualized consideration pada kepemimpinan transformasional ditandai dengan pemimpin yang menghormati bawahan, menyayangi mereka, memuaskan kebutuhan dan perasaan mereka secara individu, dan memberikan mereka dukungan. Hal ini mirip dengan individualized care yang ada pada kepemimpinan benevolent leadership. Bedanya, benevolent leadership bukan hanya baik (murah hati) terkait pekerjaan, tapi juga terkait urusan pribadi. Benevolent leadership juga berorientasi jangka panjang dan termasuk di dalamnya perilaku memaafkan (forgiving) dan melindungi (protection) (Cheng et al., 2004). Perbedaan lainnya, individualized consideration terjadi dalam situasi perlakuan dan hak yang sama antara atasan dan bawahan sebagaimana budaya negara Barat. Sementara itu, benevolent leadership terjadi pada situasi dengan perbedaan otoritas dan jarak kekuasaan yang tinggi (Cheng et al., 2004). Pada penelitian ini, atasan menunjukkan perhatian yang bukan hanya terkait pekerjaan, tapi juga terkait urusan pribadi. Contohnya atasan bertanya dan mau tahu tentang keadaan bawahan di luar pekerjaan (responden no. 21). Selain itu, atasan juga melindungi (protection) dan memaafkan (forgiving) misalnya mengayomi dan tidak selalu menyalahkan anak buah (responden no. 26).

Modeling pada kepemimpinan transformasional menekankan bahwa pemimpin harus dapat memimpin dengan contoh (lead by example) untuk dapat membentuk paradigma integritas. Berbeda dengan moral leadership yang lebih menekankan pada perilaku tidak mau menang sendiri, termasuk di dalamnya tidak menyalahgunakan kekuasaan untuk kepentingan sendiri (Cheng at al., 2004). Pada penelitian ini, perilaku membentuk integritas oleh atasan lebih menekankan pada tindakan tidak menyalahgunakan kekuasaan untuk kepentingan sendiri. Misalnya integritas tinggi dengan bersikap jujur, setia pada hati nurani dan kode etik dalam menghadapi Wajib Pajak (responden no. 40).

High performance standard pada kepemimpinan transformasional menunjukkan ekspektasi atasan yang menginginkan agar bawahan melakukan kinerja yang tinggi dengan kualitas terbaik. Hal ini mirip dengan kekakuan (rigorousness) dan ajaran (doctrine) yang ada dalam authoritarian leadership. Bedanya yaitu authoritarian leadership didasarkan pada situasi jarak kekuasaan antara atasan dan bawahan tinggi. Legitimasi kekuasaan dari authoritarian leadership berasal dari peran sebagai bawahan yang telah terinternalisasi pada diri 
bawahan, sehingga mereka melakukan pekerjaan bukan hanya sekedar karena tanggung jawab (Cheng et al., 2004). Pada penelitian ini, perilaku atasan yang menginginkan agar bawahan melakukan kinerja yang tinggi didasarkan pada situasi jarak kekuasaan yang tinggi. Studi Hofstede et al. (2010) menyatakan bahwa masyarakat Indonesia mempunyai ciri jarak kekuasaan yang tinggi. Dengan kata lain, perilaku atasan lebih mengarah pada dimensi authoritarian leadership.

Berdasarkan jawaban responden yang lebih mengarah kepada paternalistic leadership serta budaya Indonesia yang memiliki jarak kekuasaan antara atasan dan bawahan tinggi, maka paternalistic leadership dipilih untuk digunakan dalam analisis selanjutnya. Paternalistic leadership sendiri yaitu gaya kepemimpinan yang menggabungkan disiplin dan kekuasaan yang kuat dengan kebajikan kebapakan dan integritas moral (Farh \& Cheng, 2000).

Setelah mendapatkan dimensi kepemimpinan yang tepat, data kemudian diolah dan dikelompokkan menggunakan dimensi-dimensi paternalistic leadership. Dimensi paternalistic leadership yang digunakan yaitu tujuh dimensi paternalistic leadership hasil penelitian Irawanto et al. (2012).

\section{Analisis Perilaku Kepemimpinan yang Ditampilkan}

Masalah penelitian yang pertama yaitu bagaimana gaya kepemimpinan yang ditampilkan oleh atasan langsung dari AR di lingkungan KPP di wilayah DKI Jakarta. Untuk itu, ditanyakan 7 pertanyaan yaitu terkait perilaku berhasil dalam mengelola anak buah, tidak berhasil dalam mengelola anak buah, pemberian tugas, hubungan personal dengan bawahan, pengembangan anak buah, pencapaian target kinerja, dan kesulitan dalam pekerjaan. Semua jawaban dari pertanyaan kemudian dikategorikan/dikelompokkan lagi ke dalam perilaku yang dianggap berhasil dan perilaku yang dianggap tidak berhasil dalam mengelola anak buah.

Tabel 3. Perilaku Kepemimpinan yang Ditampilkan (Persepsi Account Representative)

\begin{tabular}{lllll}
\hline \multicolumn{1}{c}{ Dimensi } & \multicolumn{2}{c}{ Berhasil } & \multicolumn{2}{c}{ Tidak berhasil } \\
\cline { 2 - 5 } & \multicolumn{1}{c}{ Jumlah } & Persentase (\%) & Jumlah & \multicolumn{1}{c}{ Persentase (\%) } \\
\hline Benevolent leadership & 1.186 & 68,87 & 193 & 40,04 \\
Visible leadership & 267 & 15,51 & 130 & 26,97 \\
Moral-impartialness leadership & 157 & 9,12 & 13 & 2,70 \\
Authoritarian leadership & 37 & 2,15 & 129 & 26,76 \\
Moral-magnanimity & 51 & 2,96 & 7 & 1,45 \\
Moral-incorruptness & 23 & 1,34 & 10 & 2,07 \\
Moral-courage leadership & 1 & 0,06 & - & - \\
\hline TOTAL & 1.722 & 100,00 & 482 & 100,00 \\
\hline
\end{tabular}

Sumber: Hasil olah data

Berdasarkan hasil olah data, terdapat 1.722 jawaban yang terkait dengan perilaku berhasil dalam mengelola anak buah dan 482 jawaban terkait dengan perilaku tidak berhasil dalam 


\section{Maya Sari}

\section{Yanki Hartijasti}

mengelola anak buah berdasarkan persepsi AR. Tabel 3 menunjukkan bahwa paternalistic leadership yang paling banyak ditampilkan dan dianggap berhasil adalah dimensi benevolent leadership (68,87\%) misalnya memberikan solusi, masukan, dan/atau arahan. Adapun ketidakberhasilan kepemimpinan dikarenakan kurang menampilkan dimensi visible leadership $(26,97 \%)$ misalnya tidak/kurang menguasai teknis pekerjaan, serta banyak menampilkan dimensi authoritarian leadership $(26,76 \%)$ misalnya bersikap otoriter/diktator.

Tabel 4. Perilaku Kepemimpinan yang Ditampilkan (Persepsi Atasan)

\begin{tabular}{lllll}
\hline \multirow{2}{*}{ Dimensi } & \multicolumn{2}{c}{ Berhasil } & \multicolumn{2}{c}{ Tidak berhasil } \\
\cline { 2 - 5 } & \multicolumn{1}{c}{ Jumlah } & Persentase (\%) & Jumlah & Persentase (\%) \\
\hline Benevolent leadership & 138 & 69,35 & 18 & 38,30 \\
Visible leadership & 39 & 19,60 & 21 & 44,68 \\
Moral-impartialness leadership & 13 & 6,53 & 1 & 2,13 \\
Moral-magnanimity & 5 & 2,51 & 3 & 6,38 \\
Authoritarian leadership & 3 & 1,51 & 4 & 8,51 \\
Moral-incorruptness & 1 & 0,50 & & - \\
\hline TOTAL & 199 & 100,00 & 47 & 100,00 \\
\hline
\end{tabular}

Sumber: Hasil olah data

Sementara itu, terdapat 199 jawaban terkait dengan perilaku berhasil dalam mengelola anak buah dan 47 jawaban terkait dengan perilaku tidak atau kurang berhasil dalam mengelola anak buah berdasarkan persepsi atasan langsung dari AR. Tabel 4 menunjukkan bahwa paternalistic leadership yang paling banyak ditampilkan dan dianggap berhasil adalah dimensi benevolent leadership $(69,35 \%)$ misalnya mendengarkan dan/atau memberi solusi. Sementara itu, ketidakberhasilan kepemimpinan dikarenakan kurang menampilkan dimensi visible leadership $(44,68 \%)$ misalnya tidak/kurang disiplin, serta banyak menampilkan dimensi authoritarian leadership (8,51\%) misalnya bersikap kaku/tidak flexible.

\section{Analisis Perilaku Kepemimpinan yang Diharapkan}

Masalah penelitian yang kedua yaitu gaya kepemimpinan atasan langsung yang diharapkan oleh AR di lingkungan KPP di wilayah DKI Jakarta. Berdasarkan hasil olah data, terdapat 689 jawaban terkait dengan perilaku kepemimpinan yang diharapkan. Tabel 5 menunjukkan bahwa benevolent leadership merupakan perilaku kepemimpinan yang diharapkan (95,65\%) oleh Account Representative. Di dalamnya termasuk perilaku pemimpin yang diharapkan saat ada kesulitan dalam pekerjaan, saat target kinerja tidak tercapai, dan terkait pengembangan potensi dan karir bawahan.

Hasil penelitian secara keseluruhan menunjukkan bahwa kepemimpinan yang ditampilkan atasan dan kepemimpinan yang diharapkan oleh AR pada KPP di wilayah DKI Jakarta adalah paternalistic leadership. Penelitian ini membuktikan bahwa paternalistic leadership 
diterapkan di Indonesia yang memiliki budaya kolektivis dan jarak kekuasaan yang tinggi sebagaimana yang dikatakan oleh Aycan (2006) dalam Irawanto et al. (2012) dan Dickson et al. (2003) dalam Yukl (2010). Penelitian ini juga secara keseluruhan menguatkan penelitian yang dilakukan Irawanto (2011) bahwa kepemimpinan di Indonesia sebagian besar adalah paternalistic leadership terbukti dengan ditampilkannya dimensi-dimensi dari paternalistic leadership.

Tabel 5. Perilaku Kepemimpinan yang Diharapkan Berdasarkan Dimensi Kepemimpinan

\begin{tabular}{lll}
\hline Dimensi & Jumlah & Persentase (\%) \\
\hline Benevolent leadership & 659 & 95,65 \\
Visible leadership & 25 & 3,63 \\
Moral-impartialness leadership & 3 & 0,44 \\
Authoritarian leadership & 1 & 0,14 \\
Moral-magnanimity leadership & 1 & 0,14 \\
\hline TOTAL & 689 & 100,00 \\
\hline
\end{tabular}

Sumber: Hasil olah data

Hasil penelitian ini menunjukkan bahwa perilaku benevolent leadership merupakan perilaku kepemimpinan yang paling banyak dipersepsikan sebagai perilaku berhasil, baik menurut atasan maupun AR pada KPP di wilayah DKI Jakarta. Chou et al. (2015) menggambarkan benevolent leadership sebagai perilaku pemimpin yang menghormati bawahan, memuaskan kebutuhan dan perasaan mereka secara individu, dan memberikan mereka dukungan. Pada penelitian ini, perilaku tersebut terbukti diterapkan oleh atasan dan dinilai berhasil oleh bawahan misalnya memberikan semangat dan dukungan kepada bawahan dan memberikan masukan dan solusi atas masalah bawahan. Chou et al. (2015) juga menggambarkan benevolent leadership sebagai perilaku pemimpin yang memaafkan (forgiving) dan melindungi (protection). Perilaku tersebut juga muncul dalam penelitian ini yaitu atasan mengayomi atau melindungi anak buah. Atasan juga ikut bertanggung jawab atas pekerjan bawahan. Contohnya membantu AR ketika Kepala Kantor menanyakan halhal yang berkaitan dengan kinerja. Sikap ini sesuai dengan dimensi budaya Indonesia yang kolektivis yaitu atasan berkewajiban melindungi bawahan sebagai ganti kesetiaan yang diberikan (Hofstede et al., 2010).

Hubungan personal antara atasan dan ARadalah dekat dan akrab dalam suasana kekeluargaan. Aycan (2006) mengatakan bahwa pemimpin paternalistik menciptakan suasana kekeluargaan di tempat kerja dengan berperilaku seperti seorang ayah kepada bawahan. Lebih lanjut Aycan (2006) mengatakan bahwa pemimpin paternalistik membangun hubungan yang dekat dan individual dengan bawahan. Contoh kedekatan/keakraban antara atasan dan AR dalam penelitian ini yaitu atasan mau berbaur 


\section{Maya Sari}

\section{Yanki Hartijasti}

dengan bawahan, bersahabat, dan berlaku akrab. Atasan juga bersikap sebagai bapak sekaligus teman yang asik untuk berbagi, serta merasa seperti keluarga sendiri.

Hasil penelitian ini juga menunjukkan bahwa atasan tidak/kurang berhasil mengelola anak buah disebabkan karena kurangnya menampilkan perilaku visible leadership. Baik AR maupun atasannya sepakat bahwa perilaku tidak/kurang bersikap disiplin, tidak/kurang rajin dalam bekerja, dan tidak/kurang konsisten sebagai perilaku visible leadership yang kurang ditampilkan. Perilaku tidak/kurang bersikap disiplin misalnya yaitu atasan sering terlambat. Adapun tidak/kurang rajin dalam bekerja misalnya malas bekerja, tidur terus, atau terlalu santai dalam meneliti berkas. Perilaku visible leadership lainnya yang masih kurang ditampilkan yaitu atasan tidak/kurang menguasai teknis pekerjaan. Penguasaan teknis pekerjaan yang dimaksud yaitu penguasaan peraturan perpajakan, teknis perpajakan, Standard Operating Procedure (SOP), dan penguasaan teknologi.

Hasil penelitian ini juga menunjukkan bahwa atasan tidak/kurang berhasil mengelola AR disebabkan karena banyak menampilkan perilaku authoritarian leadership. Authoritarian sendiri mengacu pada perilaku seorang pemimpin yang menegaskan otoritas dan kontrol mutlak, serta menekankan ketaatan pada bawahan (Chou et al., 2015). Kepemimpinan ini yang didasarkan pada situasi jarak kekuasaan antara atasan dan bawahan tinggi (Cheng et al., 2004). Perilaku authoritarian leadership dalam penelitian ini misalnya pemimpin bertindak otoriter/diktator dengan memaksakan kehendaknya, menekan bawahan dan terlalu ketat mengawasi anak buah, serta pemimpin bersikap kaku/tidak fleksibel.

Perilaku authoritarian leadership dalam penelitian ini juga banyak dipersepsikan oleh atasan dan AR sebagai perilaku tidak/kurang berhasil. Pellegrini dan Scandura (2008) mengatakan bahwa authoritarian berkorelasi negatif terhadap outcomes bawahan, seperti komitmen dan kepuasan anggota tim terhadap pemimpin tim (Cheng et al., 2002) dalam Pellegrini \& Scandura(2008). Walaupun demikian, penelitian ini menemukan beberapa perilaku authoritarian yang dianggap berhasil oleh AR yaitu perilaku tegas, teliti, dan orientasi terhadap pencapaian target.

Hasil analisis juga menunjukkan bahwa benevolent leadership merupakan perilaku kepemimpinan yang diharapkan $(95,65 \%)$ oleh AR pada KPP di wilayah DKI Jakarta. Jika dibandingkan dengan harapan atasan terhadap AR sebagaimana ditunjukkan tabel 6 , terlihat bahwa atasan mengharapkan AR aktif secara mandiri berusaha untuk mencari solusi/jalan keluar pada saat AR mengalami kesulitan dalam pekerjaan, tekun dan semangat untuk maju, mau memperbaiki diri, dan mau menerima evaluasi. 
Tabel 6. Perbandingan Perilaku Antara yang Diharapkan Account Representative dengan yang Diharapkan Atasan

\begin{tabular}{|c|c|c|c|c|}
\hline \multirow{2}{*}{ Pertanyaan } & \multicolumn{2}{|c|}{ Harapan AR } & \multicolumn{2}{|l|}{ Harapan Atasan } \\
\hline & Perilaku & Persentase & Perilaku & Persentase \\
\hline \multirow{3}{*}{$\begin{array}{l}\text { Jika target tidak } \\
\text { tercapai }\end{array}$} & $\begin{array}{l}\text { Memberikan solusi, } \\
\text { masukan, dan/atau } \\
\text { arahan }\end{array}$ & 30,80 & Mau memperbaiki diri & 32,14 \\
\hline & $\begin{array}{l}\text { Memberi semangat } \\
\text { dan/atau dukungan }\end{array}$ & 29,28 & Mau menerima evaluasi & 28,57 \\
\hline & $\begin{array}{l}\text { Melakukan diskusi } \\
\text { dan evaluasi }\end{array}$ & 17,87 & Berusaha mencapai target & 21,43 \\
\hline \multirow{2}{*}{$\begin{array}{c}\text { Saat } \\
\text { menghadapi } \\
\text { kesulitan dalam } \\
\text { pekerjaan }\end{array}$} & $\begin{array}{c}\text { Mendengarkan } \\
\text { dan/atau } \\
\text { membantu mencari } \\
\text { solusi }\end{array}$ & 76,44 & Mencari solusi & 66,67 \\
\hline & $\begin{array}{c}\text { Membantu } \\
\text { pekerjaan AR }\end{array}$ & 9,78 & $\begin{array}{l}\text { Semangat dan tidak } \\
\text { menyerah }\end{array}$ & 12,50 \\
\hline \multirow{3}{*}{$\begin{array}{c}\text { Pengembangan } \\
\text { \& karir }\end{array}$} & Eskalasi ke pihak lain & 6,22 & Mau berusaha & 8,33 \\
\hline & $\begin{array}{c}\text { Tekun dan semangat } \\
\text { untuk maju }\end{array}$ & 37,50 & $\begin{array}{l}\text { Memberi } \\
\text { kesempatan/dukungan }\end{array}$ & 63,68 \\
\hline & $\begin{array}{c}\text { Meningkatkan } \\
\text { kompetensi }\end{array}$ & 41,67 & Membimbing/mengarahkan & 17,41 \\
\hline
\end{tabular}

\section{KESIMPULAN}

Berdasarkan penelitian ini,gaya kepemimpinan yang ditampilkan oleh atasan langsung ARpadaKPP di wilayah DKI Jakarta adalah paternalistic leadership dengan dimensi benevolent leadership sebagai perilaku yang paling banyak ditampilkan dan dianggap berhasil. Sementara itu, ketidakberhasilan kepemimpinan atasan dikarenakan kurang menampilkan dimensi visible leadership dan banyak menampilkan dimensi authoritarian leadership. Penelitian ini juga menunjukkan bahwa gaya kepemimpinan yang diharapkan oleh AR pada KPP di wilayah DKI Jakarta adalah paternalistic leadership dengan dimensi benevolent leadership sebagai perilaku yang paling banyak diinginkan. Adapun yang diharapkan oleh atasan yaitu AR mau aktif secara mandiri berusaha untuk mencari solusi pada saat mereka mengalami kesulitan dalam pekerjaan, tekun dan semangat untuk maju, mau memperbaiki diri, dan mau menerima evaluasi. 


\section{Maya Sari}

\section{Yanki Hartijasti}

\section{KETERBATASAN PENELITIAN}

Adapun keterbatasan dalam pelaksanaan penelitian ini adalah bahwa penelitian ini hanya meneliti perilaku kepemimpinan yang ditampilkan dan perilaku kepemimpinan yang diharapkan berdasarkan persepsi AR dan atasannya, belum secara jelas mengukur efektivitas dari perilaku kemimpinan atasan. Oleh karena itu, penelitian selanjutnya diharapkan dapat juga mengukur efektivitas dari perilaku kemimpinan tersebut.

Dari seluruh kuesioner yang telah disebar, response rate yang didapat dalam penelitian ini tidak maksimal. Tidak semua AR dan atasan yang dipilih mengisi kuesioner yang disebarkan. Oleh karena itu, penelitian selanjutnya sebaiknya memperhatikan jarak waktu penelitian. Jarak penelitian yang panjang dapat mengantisipasi proses perizinan yang cukup lama. Waktu penelitian yang cukup juga dapat mengantisipasi responden yang sibuk atau yang sedang di luar kota agar tetap dapat kesempatan mengisi kuesioner yang diberikan. Dengan begitu, jumlah responden yang diinginkan juga dapat bertambah.

Selain itu, penelitian ini merupakan studi yang hanya dilakukan untuk KPP di wilayah DKI Jakarta sehingga hasil penelitian ini hanya dapat menjadi bahan pembelajaran untuk KPP di lingkungan DKI Jakarta dan tidak dapat digeneralisir untuk Direktorat Jenderal Pajak. Oleh karena itu, sampel yang digunakan dalam penelitian selanjutnya hendaknya diperluas bukan hanya untuk KPP di wilayah DKI Jakarta dan bukan hanya untuk jabatan Account Representative sehingga dapat menjadi bahan pembelajaran untuk Direktorat Jenderal Pajak secara umum.

\section{DAFTAR PUSTAKA}

Arifin, G. 2016. Perlunya reformasi pajak. Desember 28, 2016. http://www.pajak.go.id/content/article/perlunya-reformasi-pajak

Armstrong, M. 2016. Armstrong's handbook of management and leadership for HR: Developing effective people skills for better leadership and management (4th ed.). Philadelphia: Kogan Page Publisher.

Aycan, Z. 2006. Paternalism: Towards conceptual refinement and operationalization. In Yang, K. S., Hwang, K. K., \& Kim, U. (Eds.), Indigenous and cultural psychology: Understanding people in context (pp. 445-466). New York: Springer.

Cheng, B. S., Chou, L. F., WU, T. Y., Huang, M. P., \& Farh, J. L. 2004. Paternalistic leadership and subordinate responses: Establishing a leadership model in Chinese organizations. Asian Journal of Social Psychology, 7(1), 89-117. 
Chou, W. J., Sibley, C. G., Liu, J. H., Lin, T. T., \& Cheng, B. S. 2015. Paternalistic leadership profiles: A person-centered approach. Group and Organization Management, 40(5), 685710. https://doi.org/10.1177/1059601115573358

Cooper, D. R., \& Schindler P. S. 2014. Business research methods (12th ed.). New York: McGraw-Hill/Irwin.

Direktorat Jenderal Pajak. (n.d.). Laporan tahunan Direktorat Jenderal Pajak 2016. Maret 1, 2018. http://www.pajak.go.id/laporan-tahunan-2016-direktorat-jenderal-pajak

Direktorat Jenderal Pajak. 2017. Laporan kinerja (lakin) Direktorat Jenderal Pajak tahun 2016. Agustus 10, 2017. www.pajak.go.id/content/laporan-kinerja-lakin-direktorat-jenderalpajak-tahun-2016

Direktorat Jenderal Pajak. 2018. Visi dan misi. Agustus 10, 2017. http://www.pajak.go.id/visi-dan-misi

Farh, J. L., \& Cheng, B. S. 2000. A cultural analysis of paternalistic leadership in Chinese organizations. In Li, J. T., Tsui A. S., \& Weldon, E. (eds.), Management and organizations in the Chinese context (pp. 94-127). London: Macmillan Press.

Gibson, J. L., Ivancevich, J. M., Donnely, J. H., \& Konopaske, R. 2012. Organizations: Behavior, structure, processes (14th ed.). New York: McGraw-Hill/Irwin.

Hemsworth, D., Muterera, J., \& Baregheh, A. 2013. Examining Bass's transformational leadership in public sector executives: A psychometric properties review. The Journal of Applied Business Research, 29(3), 853-862. https://doi.org/10.19030/jabr.v29i3.7785

Hofstede, G. H., Hofstede, G. J., \& Minkov, M. 2010. Cultures and organizations: Software of the mind (3rd ed.). New York: McGraw-Hill.

Irawanto, D. W. 2011. Exploring paternalistic leadership and its application to the Indonesian contexts (Doctoral dissertation). Februari 5, 2018. https://mro.massey.ac.nz/bitstream/handle/10179/2482/02_whole.pdf? sequence=1 \&isAllowe $d=y$

Irawanto, D. W., Ramsey, P. L., \& Tweed, D. C. 2012. Exploring paternalistic leadership and its application to the Indonesian public sector. International Journal of Leadership in Public Services, 8(1), 4-20. https://doi.org/10.1108/17479881211230637

Irawanto, D. W. 2016. Mencari gaya kepemimpinan yang tepat untuk Indonesia: Perspektif budaya nasional, kepemimpinan transformasional dan kepemimpinan paternalistik. Journal of Management and Business Review, 13(2), 263-277.

Julianto, P. A. 2018. Penerimaan perpajakan 2017 capai Rp 1.339 triliun. Juli 13, 2017. https://ekonomi.kompas.com/read/2018/01/02/184405726/penerimaan-perpajakan-2017capai-rp-1339-triliun

Kementerian Keuangan Republik Indonesia. 2014. Peraturan Menteri Kevangan Republik Indonesia nomor 206.2/PMK.01/2014 tentang organisasi dan tata kerja 


\section{Maya Sari}

\section{Yanki Hartijasti}

instansi vertikal Direktorat Jenderal Pajak. Jakarta: Kementerian Keuangan Republik Indonesia.

Kementerian Keuangan Republik Indonesia. 2015. Peraturan Menteri Keuangan Republik Indonesia nomor 79/PMK.01/2015 tentang Account Representative pada Kantor Pelayanan Pajak. Jakarta: Kementerian Keuangan Republik Indonesia.

Kreitner, R., \& Kinicki, A. 2013. Organizational behavior (10th ed.). New York: McGrawHill/lrwin.

Krippendorff, K. 2012. Content analysis: An introduction to its methodology (3rd ed.). California: SAGE Publications, Inc.

Kusuma, H. 2017. Sudah 9 tahun setoran pajak RI tak pernah capai target. Juli 24, 2018. https://finance.detik.com/berita-ekonomi-bisnis/d-372811 1/sudah-9-tahun-setoran-pajak-ritak-pernah-capai-target

Mayring, P. 2014. Qualitative content analysis: Theoretical foundation, basic $\begin{array}{lllll}\text { procedures and software solution. Agustus } & 2017 .\end{array}$ https://www.ssoar.info/ssoar/handle/document/39517

Northouse, P. G. 2013. Kepemimpinan: Teori dan praktik (Edisi ke-6) (Ati Cahayani, Penerjemah). Jakarta: PT Indeks.

Pellegrini, E. K.,\& Scandura, T. A. 2008. Paternalistic leadership: A review and agenda for future research. Journal of Management, 34(3), 566-593. https://doi.org/10.1177/01949206308316063

Republik Indonesia. 2014. Undang-Undang nomor5 Tahun 2014 tentang Aparatur Sipil Negara. Lembaran Negara RI Tahun 2014, No. 6. Sekretariat Negara. Jakarta.

Sakti, N. W. 2014. Tugas berat Dirjen Pajak yang baru. April 24, 2018. https://www.kompasiana.com/frans/tugas-berat-dirjen-pajak-yangbaru_54f3ade6745513942b6c7daf

Schreier, M. 2014. Qualitative content analysis. In Flick, U. (eds.), The SAGE handbook of qualitative data analysis (pp. 170-183). London: SAGE Publications Ltd.

Suryani, A. O., van de Vijver, F. J. R., Poortinga, Y. H., \& Setiadi, B. N. 2012. Indonesian leadership styles: A mixed-methods approach. Asian Journal of Social Psychology, 15(4), 290303. https://doi.org/10.1111/j.1467-839X.2012.01384.x

Wahab, S., Rahmat, A., Yusof, M. S., \& Mohamed, B. 2016. Organization performance and leadership style: Issues in education service. Procedia - Social and Behavioral Sciences, 224, 593-598. https://doi.org/10.1016/j.sbspro.2016.05.447

World Bank. 2018. Tax revenue (\% of GDP). April 25, 2018. https://data.worldbank.org/indicator/GC.TAX.TOTL.GD.ZS

Yukl, G. 2010. Kepemimpinan dalam organisasi (Edisi ke-7) (Ati Cahayani, Penerjemah). Jakarta: PT Indeks. 